\title{
RESEARCH
}

Open Access

\section{Patterns of ecstasy use amongst live music event attendees and their opinions on pill testing: a cross sectional study}

Madeleine Southey ${ }^{1+}$, Ashwini Kathirgamalingam ${ }^{1 \dagger}$, Benjamin Crawford ${ }^{1 \dagger}$, Rohan Kaul ${ }^{1 \dagger}$, Jack McNamara ${ }^{1 \dagger}$, Franklin John-Leader ${ }^{3}$, Jenny Heslop ${ }^{3}$ and Sabrina Winona Pit ${ }^{1,2^{*}}$ (i)

\begin{abstract}
Background: Pill testing services could potentially be used to reduce drug-related harm. This study aims to identify patterns of ecstasy use among live music event attendees; explore the opinions and potential usage of illicit pill testing programs and examine factors associated with the likelihood of still taking a pill containing a potential harmful substance.

Methods: A cross-sectional survey was completed by 760 people attending a major Australian live music event in 2017. Results: The most commonly used drug in the last 12 months was ecstasy (73.9\%). About $5 \%$ of people who use drugs had sought medical attention due to consumption of ecstasy. People who use drugs agreed "a lot" that pill testing should be provided for free at live music events (82.2\%) and that it should be combined with harm reduction advice (62.9\%). Additionally, 32\% of all participants agreed 'a lot' that they would be more likely to take illicit drugs at a music festival if pill-testing services were present. However, if people perceived that a harmful substance was detected in their drugs after using a pill testing service, $52.3 \%$ of people who have used illicit drugs reported that they would 'not at all' be likely to still consume the drug. They also reported that they would still take a pill if testing demonstrated the presence of unintended MDMA-type substances (70.3\%), amphetamines (31.2\%) or ketamine (27.8\%). Multivariate analyses demonstrated that only increased frequency of ecstasy use was significantly associated with taking a pill despite pill testing services detecting a harmful substance. Gender, age, alcohol and previously seeking ecstasy-related medical attention were not associated in the multivariate analyses.

Conclusions: A high proportion of live music attendees consume alcohol and ecstasy. Both people who have and who have not used illicit drugs support the implementation of pill testing services. People reported they would change their consumption patterns according to the results given by pill testing services. The findings may be used to stimulate public debate, and assist drug and alcohol policy makers in the implementation of harm minimisation strategies such as combining pill testing services with harm reduction advice.
\end{abstract}

Keywords: Pill testing, Ecstasy, MDMA, Harm reduction, Festivals, Public health

\footnotetext{
* Correspondence: s.pit@westernsydney.edu.au

${ }^{\dagger}$ Madeleine Southey, Ashwini Kathirgamalingam, Benjamin Crawford, Rohan Kaul and Jack McNamara contributed equally to this work.

'University Centre for Rural Health, School of Medicine, Western Sydney University, 62 Uralba Street, PO Box 3074, Lismore, NSW 2480, Australia

${ }^{2}$ Faculty of Medicine and Health, University Centre for Rural Health, Lismore, Australia

Full list of author information is available at the end of the article
}

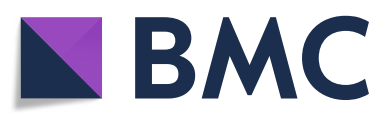

(- The Author(s). 2020 Open Access This article is licensed under a Creative Commons Attribution 4.0 International License, which permits use, sharing, adaptation, distribution and reproduction in any medium or format, as long as you give appropriate credit to the original author(s) and the source, provide a link to the Creative Commons licence, and indicate if changes were made. The images or other third party material in this article are included in the article's Creative Commons licence, unless indicated otherwise in a credit line to the material. If material is not included in the article's Creative Commons licence and your intended use is not permitted by statutory regulation or exceeds the permitted use, you will need to obtain permission directly from the copyright holder. To view a copy of this licence, visit http://creativecommons.org/licenses/by/4.0/. The Creative Commons Public Domain Dedication waiver (http://creativecommons.org/publicdomain/zero/1.0/) applies to the data made available in this article, unless otherwise stated in a credit line to the data. 


\section{Background}

Ecstasy use and its associated risk profile has become increasingly relevant in western society, with Australia ranking as the highest per capita consumer of the drug in the world as per the 2014 United Nations World Drug Report [1]. A survey conducted by the Ecstasy and Related Drugs Reporting System (EDRS) in 2017 revealed it to be the most popular illicit drug for $36 \%$ of respondents who had used psychostimulants in the last 6 months [2]. Trends in the place of consumption indicate that the majority of ecstasy use occurs at public entertainment events and venues, with live music events being the 2nd most frequent location for ecstasy consumption in Australia [2]. From a wider sample of the Australian population 14 years and over, 400,000 people (2.2\%) had used ecstasy in the last 12 months, whilst general illicit drug use in the same time period was reported amongst $15.6 \%$ of respondents [3]. The use of such illicit drugs remains highest in the 20-29 age category (32\%) [3], with the median age of ecstasy use being 28 years [3]. Illicit drug use costs the Australian economy $\$ 8$ billion annually; this includes losses in productivity, health care costs and those associated with combatting trafficking and production [4].

Ecstasy is a prohibited substance as per The Drug Misuse and Trafficking Act 1985 [5]. Consequent to the drug primarily being sourced through illegal avenues, there exists a lack of regulation and quality assurance associated with its production, creating significant risk to consumers who are often exposed to adverse side effects from added substances and impurities. As of 2016, almost $9.3 \%$ of the participants surveyed who had taken drugs had been the victim of an 'illicit drug related incident', which ranged from a mild reaction to serious adverse health outcomes; injury or death [3].

Many studies internationally, such as Israel [6] and the UK $[7,8]$, have explored the morbidity and mortality associated with ecstasy, including headaches, dehydration, agitation, hypertension, hyperthermia, loss of consciousness, cerebral oedema, serotonin syndrome, multi-organ failure and in some instances, sudden death [6-8]. Overdoses involving ecstasy pills and the added substances they contain have also been reported amongst users, with $58 \%$ of stimulant related overdose respondents attributing their overdose to the consumption of ecstasy in 2016-2017 [2].

Drug markets are not stable and vary per country. A 2006 U.S. study found that, based on testing the content of ecstasy, a large proportion of ecstasy sourced from users (46\%) did not contain any of its active ingredient; 3,4-Methylenedioxymethamphetamine (MDMA), and $15 \%$ of those tested contained a mixture of MDMA and other miscellaneous substances. The most common contaminant being Methylenedioxyamphetamine (MDA), methamphetamine, caffeine, dextromethorphan (DXM) and pseudo-ephedrine [9]. There were other substances detected including ketamine, dimethoxyamphetamine and heroin, albeit in a small percentages [9]. A 2012 Dutch study found that the occurrence of adverse events associated with ecstasy use, such as palpitations, agitation, hyperthermia and seizures could be attributed to the presence of contaminants such as MDA and metachlorophenylpiperazine (mCPP) [10]. Australia Drug Trends 2017 [2] also found increased availability of more potent forms of ecstasy when compared to previous years, raising concerns of increased potential harm for users.

These underlying dangers mean some organisations advocate for pill testing. For example, the Australian Drug Law Reform Foundation of Australia, have lobbied for legislative changes that allow pill testing services at Australian live music events as a means of harm minimisation [11]. The principle of harm minimisation formed the basis of the Australian National Drug Strategy since 1985. The harm minimisation framework encompasses three pillars: supply reduction, demand reduction and harm reduction, [12]. Pill testing falls under the principle of harm reduction, which Harm Reduction International defines as 'policies, programs and practices that aim to reduce the harms associated with the use of psychoactive drugs in people unable or unwilling to stop' [13].

Internationally, many countries throughout Europe have existing pill testing facilities or 'drug checking services' which have been legislated for and instituted at festivals over the last 25 years as a harm minimisation strategy [14-16]. Success has been seen in various areas from implementation of this harm reduction strategy, including rapid on-site identification of contaminants and purity, identification of contaminated pill presses or batches [14], facilitation of contact between health services and ecstasy users [15], as well as serving as the basis for effective public warning systems in generating awareness of circulating harmful batches $[15,16]$.

Regularly, there is media attention surrounding pill testing at live music events which is presented by reporters and include the views of predominantly authority groups and political leaders on the topic [17, 18]. The at-risk population likely to utilise pill testing services appear to be underrepresented, and underreported. Few studies have examined pill testing in the context of Australian ecstasy and illicit drug usage, although the evidence is increasing. Previous papers have analysed the accuracy of pill testing, as seen in an Australian study conducted in 2005 by Camilleri \& Caldicott [19]. More recently, a few Australian studies have assessed public opinion on pill testing. An online survey conducted in 2013 by the National Drug and Alcohol Research Centre 
[20] revealed $82.5 \%$ of respondents supported the implementation of a pill testing service. However, a much higher proportion of people in this survey had used ecstasy, with $47.7 \%$ asserting they had consumed ecstasy [20] versus the $8 \%$ found in National surveys across Australia [3]. Although the results represented the opinions of the Australian youth on this issue, the study only ascertained whether the individuals were in support of or against pill testing. There is a need to explore the role and expectations of pill testing services and their value in harm reduction at Australian live music events. A 2016 study investigated the perceptions of music festival attendees in detail and showed similar support for pill testing services with $86.5 \%$ of participants believing that pill testing services could help reduce harm [21]. Similar results were found by another recent study conducted by Barratt et al., whereby it was found that $94 \%$ would utilise a pill testing service at a festival [22]. This study builds further on the 2016 work conducted by Day et al. [21]. Since the 2016 survey [21], there have been a number of high profile deaths in Australia at live music events from drug overdose [23], which may have potentially influenced the opinions of live music festival attendees. Additionally, this study will focus on the opinions of ecstasy users in particular.

This paper aims to:

1. Identify characteristics and patterns of Ecstasy/ MDMA use among live music event attendees

2. Explore the opinions of live music event attendees on pill testing programs

3. Identify the proportion of people that have used illicit drugs that would still take a pill after results of pill testing show the presence of unintended drugs or substances

4. Examine among people who have used illicit drugs which factors are associated with the likelihood of still taking a pill despite a pill testing service detecting a harmful substance in the pill.

\section{Methods}

\section{Study design}

A cross-sectional survey was conducted.

\section{Setting, participants and recruitment}

Eligible participants were those aged over 18 attending a three-day large mixed-genre live music event in New South Wales in 2017. Surveys were distributed by five members of the research team throughout the course of the festival between $9 \mathrm{am}$ and $12 \mathrm{pm}$ each day. The five members were in their early twenties and consisted of two females and three males. The rationale for surveying between these times was to avoid intoxicated attendees later in the day. Potential participants were approached face-to-face and invited to complete the paper-based survey. Researchers were equipped with RSA (Responsible Service of Alcohol) skills to recognise those who may have been under the influence of alcohol and these individuals were excluded from the survey. Participants were given a Participant Information Statement and were told what was involved and what the study aims were. The survey was completed anonymously to ensure confidentiality. No identifying information was collected to ensure anonymity of participants. A self-completed survey format was used rather than an interview format, to minimise any discomfort regarding the sensitive nature of the questions. Completion of the survey was taken as consent.

\section{Outcome measures}

The survey was adapted from the 2016 survey by Day et al. [21] The study by Day et al. was conducted at the same festival the year prior to the current study and included the same target population. Additionally, similar recruitment methods were used for both surveys. The 2016 survey was completed by 625 people. The 2017 survey included additional questions based on current literature and expert opinion (See Additional file 1). All participants completed a core set of questions regarding demographics, employment and study, sexual orientation, relationship status, alcohol consumption and Likert scale questions where participants were able to choose to what extent they agreed with certain statements about pill testing and its potential effectiveness at live music events. Alcohol consumption was assessed using questions from the World Health Organisation Alcohol Use Disorders Identification Test: The AUDIT-C [24]. Attitude questions towards pill testing were derived from a previous study [21]. The attitude questions were preceded with the following statement: "Pill testing services could test drugs by taking a small sample. A reagent testing kit is used to test this sample, gathering information on its contents. The user can then be informed of the presence of potentially harmful ingredients/substances." An open-ended question was added asking whether patrons had any concerns about pill testing at music festivals.

The second section was only completed by people who reported ever having taken illicit drugs. Questions regarding the use of illicit drugs were derived from the National Drug Strategy Household Survey [3]. Questions measured type of drug used in the last 12 months, detailed questions about ecstasy use, how concerned they were about their health in relation to content and/ or purity of illicit drugs and if they would utilise pill testing services. To identify how participants perceived that pill testing services would influence their behaviour, participants were asked a general question: "If a harmful 
substance was detected in your drugs using the pill testing service, how likely would you be to still consume them?" with answers ranging between 'not at all', 'a little', 'somewhat' and 'a lot'. Participants were also asked a more specific question: "Would you still take a drug if the results of a drug testing kit/ pill testing service indicated the presence of the following unintended drugs?". The response options were: 'yes', 'no' or 'don't know'. (See Additional file 1 for full list of drugs). Open-ended questions asked about other substances individuals had consumed at the same time as ecstasy and the amount they would be willing to pay for the service if it were not free. Two pilot testing sessions were conducted during survey development to test the data collection tool on groups of young adults $(n=15$ and $n=10)$. The 1 st pilot-tests was conducted among students and young people directly known to the researchers. This group was chosen because the music festival is attended mainly by young people, and thus represented the target population. The second pilot test was conducted among university students.

\section{Statistical methods}

Chi-square tests were used to determine whether alcohol use was associated with the likelihood of altering drug taking behaviours based on pill testing results as well as for determining the association between those that had used illicit drugs or not with attitudes towards pill testing. $P$-values less than 0.05 were considered to indicate statistical significance.

Among MDMA users, the question "If a harmful substance was detected in your drugs using the pill testing service, how likely would you be to still consume them?" was categorised into: "not at all" versus "would consider". The "would consider" group included those that had answered "a little", "somewhat" or "a lot". Logistic regression was used to calculate crude and adjusted odds ratios to identify which factors were significantly associated with MDMA users consuming a pill even if a harmful substance was detected in their drugs after using a pill testing service. SPSS Version 22 was used.

\section{Results}

\section{Socio-demographics and drug use characteristics and patterns}

The survey was completed by 760 people between the ages of 18 and 56 and took approximately $5 \mathrm{~min}$ to complete.

\section{Sample description}

The majority of participants were male (55\%), aged 1821 (59.6\%), single (50.8\%), heterosexual (91.3\%), employed (92.6\%) and/or fulltime students (40.6\%) (Table 1). Of all participants, $40.9 \%$ reported using
Table 1 Participant characteristics $(N=760)$

\begin{tabular}{|c|c|c|}
\hline & $2017 \%$ & Comparison data $2016^{\mathbf{a}} \%$ \\
\hline \multicolumn{3}{|l|}{ Gender $(n=758)$} \\
\hline Male & 55.0 & 39.0 \\
\hline Female & 43.7 & 61.0 \\
\hline Other & 1.3 & 0.5 \\
\hline \multicolumn{3}{|l|}{ Age $(n=754)$} \\
\hline $18-19$ & 28.2 & - \\
\hline $20-21$ & 31.6 & - \\
\hline $22-23$ & 22.3 & - \\
\hline $24+$ & 17.9 & - \\
\hline \multicolumn{3}{|l|}{ Relationship status ( $n=756$ ) } \\
\hline Married/ de facto & 4.8 & 1.6 \\
\hline Single & 50.8 & 56.8 \\
\hline In a relationship & 43.2 & 41.0 \\
\hline Separated/divorced/widowed & 0.8 & 0.6 \\
\hline \multicolumn{3}{|l|}{ Sexuality $(n=750)$} \\
\hline Heterosexual & 91.3 & 90.4 \\
\hline Homosexual & 2.7 & 2.6 \\
\hline Bisexual & 4.8 & 5.9 \\
\hline Other & 1.2 & 1.1 \\
\hline \multicolumn{3}{|l|}{ Employment status $(n=757)^{b}$} \\
\hline Full time student & 40.6 & 48.9 \\
\hline Part time student & 5.8 & 7.2 \\
\hline Employed & 92.6 & 87.5 \\
\hline Unemployed & 1.6 & 12.5 \\
\hline Other & 0.5 & 0.5 \\
\hline \multicolumn{3}{|l|}{ Hours worked per week $(n=744)$} \\
\hline $0-10$ & 13.4 & - \\
\hline $11-20$ & 21.1 & - \\
\hline $21-30$ & 17.2 & - \\
\hline $31-40$ & 35.4 & - \\
\hline $41+$ & 12.9 & - \\
\hline
\end{tabular}

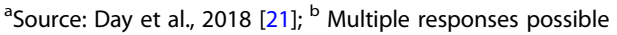

alcohol 2-3 times per week. Most participants reported having used illicit drugs (83.9\%) in their lifetime and the most commonly used drugs in the last 12 months were ecstasy/MDMA (73.9\%), cannabis (64.3\%) and cocaine $(45.5 \%)$ (Table 2). Some people who have used illicit drugs reported having time off work due to illicit drug use $(16.7 \%)$ and just over one in four reported that they had gone to work or study despite feeling that they should have taken sick leave due to their use of illicit drugs (Table 2).

\section{Comparison with 2016 sample}

The 2017 sample differed when compared to the Day et al. 2016 study sample [21]. In 2016, 39\% were 
Table 2 Prevalence drug and alcohol use among participants $(N=760)$

\begin{tabular}{|c|c|c|}
\hline Variable & $2017 \%$ & Comparison data $2016^{\mathbf{a}} \%$ \\
\hline \multicolumn{3}{|l|}{ ILLICIT DRUGS } \\
\hline Ever used illicit drugs $(n=758)$ & 83.9 & - \\
\hline \multicolumn{3}{|l|}{ Drugs used in the last 12 months $(n=747)$} \\
\hline Ecstasy/MDMA & 73.9 & 59.8 \\
\hline Cannabis & 64.3 & 63.9 \\
\hline Cocaine & 45.5 & 34.1 \\
\hline Hallucinogens & 25.3 & 20.2 \\
\hline Amphetamine & 21.4 & 18.4 \\
\hline Recreational Pharmaceutical drugs & 17.4 & 13.6 \\
\hline Inhalants & 17.4 & 8.4 \\
\hline Ketamine & 12.9 & 12.5 \\
\hline Methamphetamine & 10.0 & 4.7 \\
\hline Synthetic cannabis & 9.0 & 4.8 \\
\hline GHB & 2.9 & 2.3 \\
\hline Steroids & 1.9 & 1.7 \\
\hline Other & 0.9 & - \\
\hline Taken time of work/ study in the last 12 months due to illicit drug use $(n=617)$ & 16.7 & \\
\hline Gone to work/ study despite feeling they should have taken sick leave due to illicit drugs use $(n=610)$ & 27.5 & \\
\hline \multicolumn{3}{|l|}{ ALCOHOL } \\
\hline \multicolumn{3}{|l|}{ Frequency of alcoholic drink $(n=758)$} \\
\hline Never & 0.1 & - \\
\hline Monthly or less & 8.2 & - \\
\hline 2-3 times per month & 38.5 & - \\
\hline 2-3 times per week & 40.9 & - \\
\hline More than 4 times per week & 12.3 & - \\
\hline \multicolumn{3}{|l|}{ Standard drinks per drinking session $(n=753)$} \\
\hline 1 to 2 & 10.0 & - \\
\hline 3 to 4 & 12.4 & - \\
\hline 5 to 6 & 22.2 & - \\
\hline 7 to 9 & 23.6 & - \\
\hline More than 10 & 31.9 & - \\
\hline \multicolumn{3}{|l|}{ Frequency $>6$ standard drinks on one occasion $(n=754)$} \\
\hline Never & 0.4 & - \\
\hline Less than monthly & 13.5 & - \\
\hline Monthly & 39.1 & - \\
\hline Weekly & 45.1 & - \\
\hline Daily or almost daily & 1.9 & - \\
\hline
\end{tabular}

aSource: Day et al., 2018 [21]

men [21], however in the 2017 sample there was a higher proportion of males to females. Relationship status was similar in both groups as was the spread of sexuality. Unemployment rates were higher in 2016 (12.5\%) [21] compared to 2017 (1.6\%). Table 2 compares drug use in 2017 compared to what was found in 2016. Reported drug use in the 2017 sample was higher for every substance than in 2016. This was especially evident for ecstasy/MDMA with $73.9 \%$ in 2017 compared with $59.8 \%$ in 2016 [21], as well as cocaine use, $45.5 \%$ in 2017 compared to $34.1 \%$ in 2016 [21]. Use of methamphetamines and inhalants in 2017 was just over double what it was in 2016 [21]. 
Among those who reported having used illicit drugs in the past $(\mathrm{n}=636)$, a high proportion $(87.8 \%)$ reported having consumed MDMA/ecstasy at a live music event (Table 3). Of this sample of MDMA/ecstasy users at festivals $(n=548)$ the majority $(82 \%)$ reported mixing MDMA/ecstasy with other substances. The most common substances that were mixed with MDMA/ecstasy included alcohol (46.8\%), cannabis (31.2\%) and cocaine
(24.5\%). The majority of MDMA/ecstasy users reported using monthly (32.1\%) or every 6 months $(30.9 \%)$ and $4.6 \%$ reported having to seek medical attention.

\section{Opinions of live music event attendees on pill testing programs}

Table 4 demonstrates all participants' attitudes towards pill testing services. The majority of participants agreed

Table 3 Characteristics of MDMA/ Ecstasy use in 2017 at live music events among participants who have ever used illicit drugs ( $N=$ 636)

\begin{tabular}{|c|c|}
\hline & Percent \\
\hline \multicolumn{2}{|l|}{ Ever used MDMA/ ecstasy at a life music event $(n=636)$} \\
\hline Ever consumed MDMA/ecstasy at a live music event & 87.8 \\
\hline Ever mixed MDMA with other substances at a life music event & 82.0 \\
\hline \multicolumn{2}{|l|}{ Most common substances mixed among MDMA users $(n=548)$} \\
\hline Alcohol & 46.8 \\
\hline Cannabis & 31.2 \\
\hline Cocaine & 24.5 \\
\hline Hallucinogens & 17.4 \\
\hline Tobacco & 9.6 \\
\hline Amphetamine & 9.6 \\
\hline Ketamine & 6.5 \\
\hline Inhalants & 4.4 \\
\hline Valium & 1.5 \\
\hline Amyl Nitrate & 0.8 \\
\hline Viagra & 0.4 \\
\hline $\mathrm{GHB}$ & 0.4 \\
\hline \multicolumn{2}{|l|}{ Amount taken $(\mathrm{mg})$ at one time at a music festival $(n=548)$} \\
\hline $1-100$ & 20.8 \\
\hline $101-200$ & 31.7 \\
\hline $201-300$ & 19.1 \\
\hline $301-400$ & 8.4 \\
\hline $401-500$ & 6.0 \\
\hline $501+$ & 14.1 \\
\hline \multicolumn{2}{|l|}{ Frequency of MDMA/ecstasy use $(n=548)$} \\
\hline Fortnightly or more & 12.9 \\
\hline Monthly & 32.1 \\
\hline 6 monthly & 30.9 \\
\hline Yearly or less & 16.0 \\
\hline Never & 8.1 \\
\hline Medical attention sought due to MDMA/ecstasy $(n=548)$ & 4.6 \\
\hline \multicolumn{2}{|l|}{ Price users are willing to pay for pill testing services? $(n=497)$} \\
\hline$\$ 0$ & 14.6 \\
\hline$\$ 1-\$ 5$ & 33.6 \\
\hline$\$ 6-\$ 10$ & 31.3 \\
\hline$\$ 11-\$ 15$ & 5.8 \\
\hline$\$ 16+$ & 14.7 \\
\hline
\end{tabular}


Table 4 Attitudes towards pill testing in $2017(N=760)$

\begin{tabular}{lllll}
\hline Total & $\begin{array}{l}\text { People who use } \\
\text { illicit drug } \\
\%\end{array}$ & $\begin{array}{l}\text { People who do not } \\
\text { use illicit drug } \\
\%\end{array}$ & $\begin{array}{l}\text { Chi-square, } \\
\mathrm{d}^{\mathbf{b}}, \mathrm{p}- \\
\text { Value }\end{array}$ & Comparison data 2016 \\
& & Percent
\end{tabular}

\begin{tabular}{|c|c|c|c|c|c|c|}
\hline \multicolumn{7}{|c|}{ Pill testing should be provided for free at live music events $(n=756)^{c, d}$} \\
\hline Not at all & 2.9 & 3.0 & 2.5 & $X=25.72, \mathrm{df}=3, p<0.001$ & Not at all/ a little & 11.8 \\
\hline A little & 2.4 & 1.7 & 5.7 & & & \\
\hline Somewhat & 15.5 & 13.1 & 27.9 & & Somewhat/ a lot & 86.2 \\
\hline A lot & 79.2 & 82.2 & 63.9 & & & \\
\hline
\end{tabular}

Pill testing should be provided at a cost at live music events $(n=754)^{c, d, e}$

$\begin{array}{llllll}\text { Not at all } & 38.9 & 37.8 & 44.6 & X=4.0, \mathrm{df}=3, p=0.26 & \text { Not at all/ a little } \\ \text { A little } & 22.8 & 22.6 & 24.0 & & \\ \text { Somewhat } & 25.1 & 26.4 & 18.2 & \text { Somewhat/ a lot } \\ \text { A lot } & 13.3 & 13.3 & 13.2 & \end{array}$

Pill testing services could help drug users seek help to reduce harm ${ }^{d}(n=743)$

\begin{tabular}{|c|c|c|c|c|c|c|}
\hline Not at all & 2.4 & 2.2 & 3.3 & $X=18.20, d f=3, p<0.001$ & Not at all/ a little & 13.5 \\
\hline A little & 3.2 & 2.7 & 5.8 & & & \\
\hline Somewhat & 19.1 & 16.9 & 30.8 & & Somewhat/ a lot & 86.5 \\
\hline A lot & 75.2 & 78.2 & 60.0 & & & \\
\hline
\end{tabular}

Pill testing services should be combined with harm reduction advice $(n=753)^{d}$

\begin{tabular}{|c|c|c|c|c|c|c|}
\hline Not at all & 3.2 & 3.2 & 3.3 & $\mathrm{X}=0.22, \mathrm{df}=3, p=0.975$ & Not at all/ a little & 15.1 \\
\hline A little & 8.4 & 8.4 & 8.3 & & & \\
\hline Somewhat & 25.9 & 25.6 & 27.5 & & Somewhat/ a lot & 84.9 \\
\hline A lot & 62.5 & 62.9 & 60.8 & & & \\
\hline
\end{tabular}

Drug sellers may use the service as a quality control mechanism $(n=751)$

$\begin{array}{llllll}\text { Not at all } & 10.5 & 10.2 & 12.4 & X=4.73, \mathrm{df}=3, p<0.192 & \text { Not at all/ a little } \\ \text { A little } & 16.6 & 15.9 & 20.7 & 31.4 \\ \text { Somewhat } & 30.4 & 29.8 & 33.1 & \text { Somewhat/ a lot } \\ \text { A lot } & 42.5 & 44.1 & 33.9 & \end{array}$

I would be more likely to take illicit drugs at a music festival if pill testing services were present $(\mathbf{n}=\mathbf{7 5 0})$

$\begin{array}{lllll}\text { Not at all } & 25.3 & 23.5 & 35.3 & X=15.46, \mathrm{df}=3, p=0.001 \\ \text { A little } & 18.0 & 17.4 & 21.0 \\ \text { Somewhat } & 24.7 & 24.4 & 26.1 \\ \text { A lot } & 32.0 & 34.7 & 17.6\end{array}$

${ }^{a}$ Source: Day et al, 2018 [21]; ${ }^{\text {b }} d f$ degrees of freedom; 'In 2016, the word 'festivals' was used instead of 'live music event'; ${ }^{\mathrm{d}}$ In 2016, the words 'drug checking services' was used instead of 'pill testing services'; ' In 2016, the question was worded as follows: "If not free, drug checking services should be provided AT-COST at festivals"

'a lot' $(79.2 \%)$ or 'somewhat' (15.5\%) that pill testing services should be provided for free at live music events. Conversely, the majority disagreed with providing pill testing services at a cost responding with 'not at all' (38.9\%) or 'a little' (22.8\%). Most agreed 'a lot' (75.2\%) and 'somewhat' (19.1\%) that pill testing services could help people that use drugs to seek help and reduce harm and similarly 'a lot' (62.5\%) and 'somewhat' (25.9\%) agreed that pill testing services should be combined with harm reduction advice.

Compared to people who do not use illicit drugs, people who use drugs were found to be significantly more likely to support pill testing being provided for free at live music events, more likely to believe that pill testing services could help people who use drugs to seek help and reduce harm, and were significantly more likely to take illicit drugs at live music events if pill testing was provided.

\section{Comparison with 2016 sample}

There was a small difference in the responses to whether pill testing should be provided for free at live music events with a higher response for those agreeing "somewhat" or "a lot" in our survey (94.7\%) compared to the 
2016 survey (86.2\%) [21]. There was a larger difference in the responses to whether pill testing should be provided at a cost at live music events with a lower response for those agreeing "somewhat" or "a lot" in our survey (38.4\%) compared to the 2016 survey (67.5\%) [21]. Compared to 2016, participants in 2017 reported slightly higher levels of agreeing 'somewhat' or 'a lot' with the statement 'Pill testing services could help drug users seek help to reduce harm' (94.3\% in 2017 versus $86.5 \%$ in 2016). Similar proportions in 2017 (88.4\%) and 2016 (84.9\%) of participants agreed 'somewhat' or 'a lot' that 'Pill testing services should be combined with harm reduction advice'. Finally, similar proportions in 2017 (72.9\%) and 2016 (68.6\%) agreed 'somewhat' or 'a lot' that drug sellers may use the service as a quality control mechanism.

Participants who had previously used illicit drugs $(\mathrm{n}=$ 636) were asked about their opinions on their pills (Table 5). Most participants agreed 'somewhat' (38.3\%) or 'a lot' (20.9\%) that they were concerned about the content and/or purity of their illicit drugs in terms of their health. When asked if they were likely to consume

Table 5 Behaviour among people that ever used illicit drugs $(N=636)$

\begin{tabular}{|c|c|c|c|}
\hline & $\%(n)$ & Comparison data $2016^{\mathbf{a}}$ & Percent \\
\hline \multicolumn{4}{|c|}{$\begin{array}{l}\text { In terms of your health how concerned are you about the conten } \\
\text { and/or purity of the illicit drugs you take }(n=618)\end{array}$} \\
\hline Not at all & 13.8 & Not at all/ a little & 47.2 \\
\hline A little & 27.0 & & \\
\hline Somewhat & 38.3 & Somewhat/ a lot & 52.8 \\
\hline A lot & 20.9 & & \\
\hline
\end{tabular}

If a harmful substance was detected in your drugs using the pill testing service, how likely would you be to still consume them? $(n=618)$

$\begin{array}{ll}\text { Not at all } & 52.3 \\ \text { A little } & 25.9 \\ \text { Somewhat } & 16.3 \\ \text { A lot } & 5.5\end{array}$

Currently, how likely are you to attempt to find out about content and/or purity of the illicit drugs you intend to take? $(n=615)$

$\begin{array}{ll}\text { Not at all } & 19.8 \\ \text { A little } & 26.7 \\ \text { Somewhat } & 27.5 \\ \text { A lot } & 26.0\end{array}$

How likely is it that you would use a free pill testing service? $(n=$ 615)

\begin{tabular}{ll} 
Not at all & 3.1 \\
A little & 6.5 \\
Somewhat & 17.1 \\
A lot & 73.3 \\
\hline a Source: Day et al, 2018 [21]
\end{tabular}

their drugs if a pill testing service found they contained a harmful substance, a large proportion of respondents were unlikely to, with responses of 'not at all' (52.3\%) and 'a little' (25.9\%) being the most prevalent. Responses were mixed in regards to how likely participants currently are to test the content and/or purity of their illicit drugs. A high proportion of participants agreed 'somewhat' $(17.1 \%)$ or 'a lot' (73.3\%) that they were likely to use a free pill testing service if it was provided at live music events.

\section{Comparison with 2016 sample}

When compared to 2016 survey data, there was a slight increase in individuals who reported being 'somewhat or 'a lot' concerned in terms of their health about the content and/or purity of illicit drugs taken from $52.8 \%$ in 2016 [21] to $59.2 \%$ in 2017. In 2016, $13 \%$ responded that they would not at all be likely to utilise a free pill testing service [21] compared to only $3.1 \%$ of individuals in 2017 . The majority of individuals in 2016 and 2017 responded that their likelihood of using a pill testing service was 'a lot' however this was higher in the 2017 cohort (73.3\%) compared to 2016 data where $54.4 \%$ responded it was 'highly likely' they would use a free drug checking service [21].

\section{Considerations of still taking a drug if the results of a drug testing kit/ pill testing service indicated the presence of unintended drugs}

Table 6 shows whether pill testing would influence drug consumption among people who use drugs, if it showed that the pill had various unintended drugs. A majority of participants indicated they would still take the drug if it contained MDMA-type substances (70.3\%), this was followed by amphetamine (31.2\%), ketamine (27.8\%), opiates (17.8\%), and methamphetamine (17\%). The 2017 findings were very similar to the 2016 data, however there was an increase from $20.9 \%$ in 2016 [21] to $27.8 \%$ in 2017 of those who would still take a pill if it unintentionally contained ketamine.

Factors associated with the likelihood of still taking a pill despite a pill testing service detecting a harmful substance in the pill

Table 7 demonstrates that the more frequently people drink, the more likely they are to consider taking a pill even if a harmful substance was detected in their drugs after using a pill testing service. Similarly, the more frequently people would consume more than six standard drinks in one session, the more likely they are to consider taking a pill even if a harmful substance was detected in their drugs after using a pill testing service.

Table 8 demonstrates that those who drink alcohol more than four times a week are more likely to consume a pill even if a harmful substance was detected in their 
Table 6 Proportion of people that have used illicit drugs that would still take a drug if the results of a drug testing kit/ pill testing service indicated the presence of unintended drugs $(n=636)$

\begin{tabular}{|c|c|c|c|c|}
\hline & $\begin{array}{l}\text { Would take } \\
\%\end{array}$ & $\begin{array}{l}\text { Would not take } \\
\%\end{array}$ & $\begin{array}{l}\text { Don't know } \\
\%\end{array}$ & $\begin{array}{l}\text { Comparison data } 2016^{1} \\
\text { Would take } \\
\%\end{array}$ \\
\hline MDMA- type substances (MDA, MDE) $(n=622)$ & 70.3 & 10.5 & 19.3 & 69.7 \\
\hline Amphetamine $(n=622)$ & 31.2 & 36.8 & 32.0 & 32.9 \\
\hline Ketamine $(n=622)$ & 27.8 & 42.1 & 30.1 & 20.9 \\
\hline Opiates $(n=622)$ & 17.8 & 41.3 & 40.8 & 15.7 \\
\hline Methamphetamine $(n=622)$ & 17.0 & 52.3 & 30.7 & 14.9 \\
\hline $2 \mathrm{C}-\mathrm{B} / \mathrm{C} / \mathrm{I}(n=622)$ & 6.4 & 43.1 & 50.5 & 7.9 \\
\hline $\operatorname{DXM}(n=621)$ & 6.0 & 44.4 & 49.6 & 7.0 \\
\hline No reaction (benign or unknown substances) $(n=622)$ & 5.9 & 41.8 & 52.3 & 6.3 \\
\hline PMA/PMMA $(n=622)$ & 3.9 & 44.2 & 51.9 & 3.8 \\
\hline Methylone $(n=622)$ & 3.2 & 45.2 & 51.6 & 3.1 \\
\hline Butylone $(n=632)$ & 3.1 & 45.2 & 51.8 & 1.8 \\
\hline $\mathrm{DOB}(\mathrm{n}=622)$ & 2.9 & 44.1 & 53.1 & 3.1 \\
\hline Naphyrone $(n=622)$ & 2.9 & 45.2 & 51.9 & 1.9 \\
\hline $\mathrm{DOI}(\mathrm{n}=622)$ & 2.4 & 43.9 & 53.7 & 3.1 \\
\hline Other $(n=622)$ & 2.1 & 42.3 & 55.6 & 2.5 \\
\hline
\end{tabular}

${ }^{1}$ Source: Day et al, 2018 [21]

drugs after using a pill testing service (crude OR 1.935, 95\%CI 1.116-3.357). Similarly, those using MDMA daily, weekly or fortnightly were more likely to consume a pill even if a harmful substance was detected in their drugs after using a pill testing service when compared to six monthly, yearly or one time users (crude OR 2.124, 95\%CI 1.457-3.097). However, multivariate analyses demonstrated that only increased frequency of MDMA use was significantly associated with taking a drug despite pill testing services detecting a harmful substance after adjusting for all other variables.

\section{Discussion}

Multivariate analyses demonstrated that only frequency of ecstasy use was significantly associated with taking a pill despite pill testing services detecting a harmful substance. Gender, age, alcohol and previously seeking ecstasy-related medical attention were not associated in the multivariate analyses with taking a pill containing harmful substance.

In univariate analyses, a correlation was found with the frequency of high risk or "binge" drinking and its association with the likelihood of still taking a pill despite a pill testing service detecting a harmful substance.

Table 7 Alcohol and its association with the likelihood of still taking a pill despite a pill testing service detecting a harmful substance in the pill among people who use drugs $(N=636)$

\begin{tabular}{|c|c|c|c|}
\hline & Would not consider & Would consider & Chi-square, $d f^{a}, p$-value ${ }^{b}$ \\
\hline \multicolumn{4}{|c|}{ How often do you have a drink containing alcohol? $(n=618)$} \\
\hline Never & 0.0 & 100.0 & $x=13.30, \mathrm{df}=4, p=0.006$ \\
\hline Monthly or less & 62.8 & 37.2 & \\
\hline 2-3 times per month & 58.5 & 41.5 & \\
\hline 2-3 times per week & 49.4 & 50.6 & \\
\hline $4+$ times weekly & 38.8 & 61.3 & \\
\hline \multicolumn{4}{|c|}{ Frequency of $6+$ standard drinks in 1 session $(n=613)$} \\
\hline Never & 0.0 & 100.0 & $x=12.03, \mathrm{df}=4, p=0.010$ \\
\hline Monthly or less & 67.9 & 32.1 & \\
\hline 2-3 times per month & 53.3 & 46.7 & \\
\hline 2-3 times per week & 48.3 & 51.7 & \\
\hline $4+$ times weekly & 33.3 & 66.7 & \\
\hline
\end{tabular}

${ }^{\mathrm{a}} d f$ degrees of freedom ${ }^{\mathrm{b}}$ Exact values used due to small numbers 
Table 8 Crude and adjusted odds ratios and multivariate logistic regression among MDMA users that would consider taking a pill, even if a harmful substance was detected compared to those who would not take the pill

\begin{tabular}{|c|c|c|c|c|c|c|c|c|c|}
\hline & \multirow[t]{2}{*}{$\%$} & \multirow[t]{2}{*}{$\boldsymbol{P}$ value } & \multirow{2}{*}{$\begin{array}{l}\text { Crude } \\
\text { OR }\end{array}$} & \multicolumn{2}{|l|}{$95 \% \mathrm{Cl}$} & \multirow[t]{2}{*}{$P$-value } & \multirow{2}{*}{$\begin{array}{l}\text { Multi- } \\
\text { variate } \\
\text { OR }\end{array}$} & \multicolumn{2}{|c|}{$95 \% \mathrm{Cl}$} \\
\hline & & & & Lower & Upper & & & Upper & Lower \\
\hline \multicolumn{10}{|l|}{ Gender } \\
\hline Male & 59.1 & 0.146 & 1.292 & 0.915 & 1.825 & .158 & 1.298 & .904 & 1.864 \\
\hline Female & 40.9 & - & 1.000 & - & - & - & 1.000 & - & - \\
\hline Age per year (continuous) & - & 0.245 & 0.974 & 0.931 & 1.018 & .153 & .965 & .919 & 1.013 \\
\hline \multicolumn{10}{|c|}{ How often do you have a drink containing alcohol? } \\
\hline Never/ monthly or less/ 2-3 times a month & 42.3 & - & 1.000 & - & - & .072 & .578 & .318 & 1.051 \\
\hline 2-3 times a week & 45.1 & 0.064 & 1.406 & 0.980 & 2.018 & .206 & .687 & .383 & 1.230 \\
\hline 4 or more times a week & 12.6 & 0.019 & 1.935 & 1.116 & 3.357 & & 1.000 & - & - \\
\hline \multicolumn{10}{|l|}{ How often do you use MDMA? } \\
\hline Six month/ yearly/ once & 49.6 & - & 1.000 & - & - & - & 1.000 & - & - \\
\hline Monthly & 35.7 & 0.002 & 2.280 & 1.364 & 3.809 & .042 & 1.775 & 1.022 & 3.082 \\
\hline Daily/weekly/fortnightly & 14.6 & $<0.0005$ & 2.124 & 1.457 & 3.097 & .004 & 1.785 & 1.203 & 2.647 \\
\hline \multicolumn{10}{|c|}{ Have you ever had to seek medical attention due to taking MDMA? } \\
\hline Yes & 4.8 & 0.049 & 2.349 & 1.003 & 5.498 & .105 & 2.173 & .850 & 5.555 \\
\hline No & 95.2 & - & 1.000 & - & - & - & 1.000 & - & - \\
\hline
\end{tabular}

There was a steady increase in the proportion of people who would consider taking a pill, even if a harmful substance was detected in their drugs after using a pill testing service, in relation to their increasing frequency of hazardous drinking. Hazardous alcohol consumption, as well as the willingness to consume a pill that may harm the individual, reflect risk-taking behaviours. It is unsurprising therefore that individuals who partake in risk-taking, hazardous alcohol consumption may also be inclined to demonstrate risk-taking behaviour associated with their pill taking habits. The link between ecstasy consumption and risk-taking behaviour is well supported in the literature [25].

Analysis of trends in amount of ecstasy consumed by people that use illicit drugs revealed that whilst the proportion of people that had ever consumed ecstasy at a live music event was high (87.8\%), 20.8\% took a relatively low dosage of MDMA/ecstasy at any one time (100 mg or less). However, $65.2 \%$ of ecstasy users consumed between 101 and $500 \mathrm{mg}$ of MDMA/ecstasy in one session and $14.1 \%$ consumed greater than $500 \mathrm{mg}$ of MDMA/ecstasy in the same time period. These results reflect a group of people putting themselves at risk of adverse effects, given that the results of a study conducted in 2012 showed that detrimental reactions were more likely to occur at MDMA dosages greater than $120 \mathrm{mg}$ [10]. It is worthy to note that the accuracy in reporting dosages ingested may be compromised by the fact that the actual MDMA content may differ from what is expected [9]. In keeping with the aforementioned high risk-taking behaviour seen among young festival goers, the frequency of ecstasy use was also relatively high; with $12.9 \%$ reporting use every 2 weeks or more and $32.1 \%$ reporting monthly use.

Our research reinforced many of the findings published by Day et al. [21]. Overall, all drug use appears to be higher in our sample than the 2016 sample. This may have been due to chance. The main demographic difference between the two samples was the gender ratio. There was also an increased reported unemployment level in the 2016 sample. All other demographics were comparable.

Another notable difference between the 2016 and 2017 studies was the increase in reported ecstasy use. Day et al. found that $59.8 \%$ of respondents had used ecstasy in the preceding 12 months [21], whereas in our study, $73.9 \%$ reported using ecstasy in that time period. This variation could potentially be explained by the difference in gender distribution between the two survey samples, with a $55 \%$ male majority in our study compared to a $61 \%$ female majority in the 2016 study [21], thus resulting in a difference in reported ecstasy use. Other confounding factors could be, for example, the frequency of attending live music events by participants but this was not measured in either study. The opinions of pill testing services were generally similar between 2016 and 2017. The most notable difference was that a lower proportion of 2017 participants agreed 'somewhat' or 'a lot' that pill testing should be provided at a cost at live music events (38.4\% in 2017 versus $67.5 \%$ in 2016). This may be explained by the lower number of ecstasy users in the 2016 sample [21]. 
The findings of our study were further supported by Barrat et al. 2017 [22] who examined the acceptability of design features of pill testing services. They found that $94 \%$ of participants in their survey would use a pill testing service at music festivals or clubs. Whilst the question posed by Barrat et al. differed in that they queried whether participants would personally use the service versus our question regarding whether participants believed pill testing should be made available in a live music event setting, both showed a large majority in favour of the implementation of pill testing [22].

Compared to the 2016 survey, our data also showed a trend that indicates individuals are more concerned about their wellbeing when consuming illicit substances and increasingly likely to utilise pill testing services. In our survey only $3.1 \%$ of individuals responded that they would be 'not at all' likely utilise a free pill testing service compared with 13\% in 2016 [21]. Almost three quarters of the individuals $(73.3 \%)$ surveyed responded that their likelihood of using a pill testing service was 'a lot'; when compared to 2016 data, where $54.4 \%$ of individuals responded it was 'highly likely' they would use a free pill testing service [21]. However, it should be acknowledged that this could be due to chance and we used convenience sampling. Future research, could examine changes in attitudes towards drug-checking over time and control for baseline differences.

Another important finding of our study is the extent to which individuals would heed the results of pill testing services if they were to be made available at Australian live music events. Over half of respondents (52.3\%) answered that if a harmful substance was detected they would be 'not at all' likely to consume the drug. An additional $25.9 \%$ responded they would be 'a little' bit likely to consume the pill. This finding is poignant for policy makers as it indicates that individuals would not only utilise pill testing services, but would also trust and act upon the outcome of such testing, therefore altering consumption habits. However, still about half of the participants said they would consider taking the drug. When these findings are combined with increased individual investigation into the content and/or purity of their pills and the increased likelihood of utilising pill testing services should they be available, it is evident that people who use drugs are interested in participating in harm minimisation programs. These would have the potential to influence individual consumption patterns and potentially prevent individuals suffering adverse health outcomes. However, we also acknowledge that a variety of preventive actions are required for specific circumstances and different population needs. We also acknowledge that the risk of not detecting harmful substances with pill-testing services, and their reliability and accuracy remains.
Pill-testing has often been at the forefront of political debate in the last decade, particularly in terms of the intersections between drug policy, law enforcement praxis and perceptions of community safety. This context needs to be recognised. Our paper may be able to add to the debate about pill-testing, contributing valuable empirical data to inform knowledge and policy reform, whilst keeping the study limitations in mind. A concern of many opponents of pill testing is whether the availability of such a service would increase the prevalence of drug taking at live music events. We asked our participants how much they agreed with the statement "I would be more likely to take illicit drugs at a music festival if pill testing services were present". We found that about one in four $(23.5 \%)$ people who use illicit drugs and about one in three people who do not use drugs (35.3\%) said they would be 'not at all' more likely to consume drugs at a festival if pill testing is available. Similarly, $34.7 \%$ of people who use drug versus $17.6 \%$ of those who do not use drug replied that they would be 'a lot' more likely to. This indicates that a proportion of attendees are more likely to consume drugs, if pill testing services were made available to them, but this proportion is smaller among those who do not take drugs. A 2011 Swiss study found that following the provision of drug checking facilities in Zurich, there was no increase in the frequency of consumption of most party drugs or in polydrug use (https://harmreductionjournal.biomedcentral.com/articles/10.1186/1477-7517-8-16).

\section{Limitations}

Self-report and the inability to draw causal relationships were limitations. Due to the nature of the survey, people participating in illegal activities, such as the consumption of illicit substances, may have been reluctant to participate due to fears of police or festival security involvement, and prosecution for divulging this information. This means those partaking in illicit activities may be underrepresented in the data results of this study and represent non-responder bias. To combat this, the survey was specifically made anonymous so it was not possible to link the survey back to people who had completed the survey.

There may also have been a response bias, as it was a voluntary survey, and those who were in favour of the implementation of pill testing may have been more eager to participate.

Readers should bear in mind that sections of the survey relied heavily on individual's knowledge of various illicit substances. Specific substances that were listed such as methylone or PMA/PMMA could also be considered a MDMA-type drug. Lack of knowledge of these substances, and their potential harm or limited awareness regarding what substances individuals were 
consuming may affect the accuracy of responses in these sections of the survey. This could skew the data for the drugs that individuals had consumed in the previous 12 months as well as the questions relating to the specific substances identified in pill testing, and whether the presence of these would affect their decision to take the drug. Participants' perception of when a drug is considered harmful would also vary by participant. The survey did not provide a definition of harmful. Another related limitation was that any substances other than MDMA were a priori labelled as potentially harmful and thus could have been considered dangerous by the participant with limited knowledge.

Another factor that may have altered people's opinions on pill testing was their knowledge of the purpose and processes involved in the testing. Those with limited knowledge on pill testing would have to rely on the explanation on the survey, and in the short amount of time that they would undertake the survey they would have to form many opinions about the process. This could be of concern as those with previous exposure to the idea of pill testing services would have had more time to reflect, question and form their opinions.

In an environment where individuals were consuming alcohol and illicit substances, severely intoxicated individuals partaking in the study could have altered the outcomes. Although this was minimised by recruiting participants in the morning and screening individuals for physical signs of intoxication (supported by RSA: Responsible Service of Alcohol training under the NSW Liquor Act 2007), it is a limitation that should be considered when interpreting the findings.

It was noted that the open-ended questions in the survey were poorly answered, resulting in considerable amounts of missing data. We therefore were not able to draw any conclusions from the open-ended questions.

\section{Conclusion}

A high proportion of live music attendees consume alcohol and drugs, especially ecstasy. This suggests that they are a high-risk group that could potentially benefit from harm minimisation strategies. Both people who have and who have not used illicit drugs support the implementation of pill testing services. People would change their consumption patterns according to the results given by pill testing services and are also in favour of pill testing services combined with harm reduction advice. Increased frequency of MDMA usage is associated with increased likelihood of taking a pill despite pill testing services detecting a harmful substance. The findings may be used to stimulate public debate, and assist drug and alcohol policy makers in the implementation of harm minimisation strategies such as combining pill testing services with harm reduction advice.

\section{Supplementary information}

Supplementary information accompanies this paper at https://doi.org/10. 1186/s13011-020-00295-1.

Additional file 1. Survey questions. Survey questions. Survey questions.

\section{Abbreviations}

2C-B/CA: 2,5-Dimethoxy-4-bromophenethylamine; AUDIT: Alcohol use disorders identification test; Cl: Confidence interval; DF: Degrees of freedom; MDA: Methylenedioxyamphetamine; EDRS: Ecstasy and related drugs reporting system; DOB: Dimethoxybromoamphetamine; DOI: 2,5- Dimethoxy4-iodoamphetamine; DXM: Dextromethorphan; GHB: Gamma hydroxybutyrate; OR: Odds ratio; MDMA: 3,4-

Methylenedioxymethamphetamine; mCPP: meta-Chlorophenylpiperazine; NSW: New South Wales; PASH: Positive adolescent sexual health; PMA: Paramethoxyamphetamine; RSA: Responsible Service of Alcohol

\section{Acknowledgements}

We thank the participants and the North Coast PASH Consortium for facilitating data collection.

\section{Authors' contributions}

MS, AK, BC, RK, JM, SP, FJL, JH designed the study. MS, AK, BC, RK, JM and FJL recruited study participants. MS, $A K, B C, R K$, and JM drafted the manuscript. Data analysis was conducted by SP, BC and RK. Data interpretation was conducted by SP, MS, AK, BC, RK, JM, with input from FJL and JH. FJL and JH provided content expertise. SP led the study. All authors contributed to developing the study materials, writing the manuscript and read and approved the final manuscript.

\section{Funding}

SP received funding from NNSWLHD to finalise the paper. No further funding has been received.

\section{Availability of data and materials}

The datasets generated and/or analysed during the current study are not publicly available due to the existing ethics approval.

\section{Ethics approval and consent to participate}

Ethics approval was obtained from The Western Sydney University Human Research Ethics Committee (No: 12212). Consent was received by participants completing the survey as per ethics approval.

Consent for publication

Not applicable.

\section{Competing interests}

The authors declare that they have no competing interests.

\section{Author details \\ ${ }^{1}$ University Centre for Rural Health, School of Medicine, Western Sydney University, 62 Uralba Street, PO Box 3074, Lismore, NSW 2480, Australia. \\ ${ }^{2}$ Faculty of Medicine and Health, University Centre for Rural Health, Lismore, Australia. ${ }^{3}$ Harm Reduction and Health Promotion Programs, HIV and Related Programs (HARP), North Coast Public Health, Mid-North Coast Local Health District, Lismore, Australia.}

Received: 21 January 2020 Accepted: 21 July 2020

Published online: 05 August 2020

\section{References}

1. United Nations Office on Drugs and Crime. World Drug Report 2014. 2014. Available from: https://www.unodc.org/documents/wdr2014/World_Drug_ Report_2014_web.pdf. [cited 2018 February]. 
2. Uporova J, Karlsson A, Sutherland R, Burns L. Australian trends in ecstasy and related Drug markets 2017: findings from the ecstasy and related drugs reporting system (EDRS), Australian Drug trends series no. 190. Sydney: National Drug and Alcohol Research Centre, UNSW Australia; 2018.

3. Australian Institute of Health and Welfare. National Drug Strategy Household Survey 2016: detailed findings. Drug statistics series no. 31. Cat. No. PHE 214. Canberra: AlHW; 2017.

4. Collins DJ, Lapsley HM. The Costs of Tobacco, Alcohol and Illicit Drug Abuse to Australian Society in 2004/05 2008. Available from: https://www.health. gov.au/internet/drugstrategy/publishing.nsf/Content/34F55AF632F6 7B70CA2573F60005D42B/\$File/mono64.pdf. [cited 2018 February].

5. Drug Misuse and Trafficking Act 1985 No 226 Section 18A, NSW. Available at: https://www.legislation.nsw.gov.au/inforce/46cd4783-9c07-6213-ce11-fba993 0ef61f/1985-226.pdf. Accessed 20 Sept 2017.

6. Halpern P, Moskovich J, Avrahami B, Bentur Y, Soffer D, Peleg K. Morbidity associated with MDMA (ecstasy) abuse: a survey of emergency department admissions. Hum Exp Toxicol. 2011;30(4):259-66.

7. Hall AP, Henry JA. Acute toxic effects of 'ecstasy' (MDMA) and related compounds: overview of pathophysiology and clinical management. BJA. 2006;96(6):678-85.

8. Henry JA, Jeffreys KJ, Dawling S. Toxicity and deaths from 3,4methylenedioxymethamphetamine ("ecstasy"). Lancet. 1992;340(8816):384-7.

9. Tanner-Smith EE. Pharmacological content of tablets sold as "ecstasy": results from an online testing service. Drug Alcohol Depend. 2006;83(3):247-54.

10. Brunt TM, Koeter MW, Niesink RJ, van den Brink W. Linking the pharmacological content of ecstasy tablets to the subjective experiences of drug users. Psychopharmacology. 2012;220(4):751-62.

11. Pill testing at music festivals needed after overdose, doctors say. Available at: http://www.abc.net.au/news/2017-01-03/drug-testing-calls-after-raveoverdose-scenic-rim/8159864. Accessed 30 July 2020.

12. Ministerial Council on Drug Strategy. National Drug Strategy 2010-2015: A framework for action on alcohol, tobacco and other drugs. 2011 [Accessed 2018 February]. Available from: http://www.nationaldrugstrategy.gov.au/ internet/drugstrategy/publishing.nsf/Content/DB4076D49F13309FCA257854 007BAF30/\$File/nds2015.pdf. Accessed 14 Feb 2018.

13. https://www.hri.global/what-is-harm-reduction Harm reduction international. Accessed 30 July 2020.

14. The Trans European Drug Information project. 2nd TEDI Trend Report. 2013. Available from: http://fileserver.idpc.net/library/Tedi_trend_report_feb2013. pdf. Accessed 30 July 2020

15. Brunt T. Drug Checking as a harm reduction tool for recreational drug users: opportunities and challenges. 2017 [Accessed 2018 February]. Available from: http://www.emcdda.europa.eu/system/files/attachments/6339/ EuropeanResponsesGuide2017_BackgroundPaper-Drug-checking-harmreduction_0.pdf. Accessed 30 July 2020.

16. Hunt N, Ashton M, Lenton S, Mitcheson L, Nelles B, Stimson G. A review of the evidence-base for harm reduction approaches to drug use. London: Forward Thinking on Drugs; 2003.

17. http://www.smh.com.au/comment/pill-testing-isnt-a-silver-bullet-to-preventdrug-deaths-but-it-is-part-of-the-solution-20151207-glh9ej.html Pill testing isn't a silver bullet to prevent drug deaths, but it is part of the solution. Accessed 30 July 2020.

18. http://theconversation.com/we-have-a-moral-obligation-to-allow-drug analysis-at-music-festivals-65144 We have a moral obligation to allow drug analysis at music festivals. Accessed 30 July 2020

19. Camilleri AM, Caldicott D. Underground pill testing, down under. Forensic Sci Int. 2005;151(1):53-8.

20. Lancaster K, Ritter A, Matthew-Simmons F. Young people's opinions on alcohol and other drug issues. National Drug and Alcohol Research Centre, University of New South Wales. 2013. Available from: https://ndarc.med. unsw.edu.au/sites/default/files/newsevents/events/RP27-young-peoplesopinions.pdf. Accessed 30 July 2020.

21. Day N, Criss J, Griffiths B, Gujral SK, John-Leader F, Johnston J, et al. Music festival attendees' illicit drug use, knowledge and practices regarding drug content and purity: a cross-sectional survey. Harm Reduct J. 2018;15(1):1.

22. Barratt MJ, Bruno R, Ezard N, Ritter A. Pill testing or drug checking in Australia: acceptability of service design features. Drug Alcohol Rev. 2018; 37(2):226-36.

23. Three people die from drug overdoses in Melbourne after 20 hospitalised, court told.. Available at: http://www.abc.net.au/news/2017-01-16/three-people-diefrom-drug-overdoses-in-melbourne/8185134. Accessed 30 July 2020.
24. Babor TF, Higgins-Biddle JC, Saunders JB, Monteiro MG. The alcohol use disorders identification test (AUDIT): quidelines for use in primary care: World Health Organization, Department of Mental Health and Substance Abuse; 2001.

25. Butler GK, Montgomery AM. Impulsivity, risk taking and recreational 'ecstasy' (MDMA) use. Drug Alcohol Depend. 2004;76(1):55-62.

\section{Publisher's Note}

Springer Nature remains neutral with regard to jurisdictional claims in published maps and institutional affiliations.
Ready to submit your research? Choose BMC and benefit from:

- fast, convenient online submission

- thorough peer review by experienced researchers in your field

- rapid publication on acceptance

- support for research data, including large and complex data types

- gold Open Access which fosters wider collaboration and increased citations

- maximum visibility for your research: over $100 \mathrm{M}$ website views per year

At BMC, research is always in progress.

Learn more biomedcentral.com/submissions 